\title{
Effect of Weight Loss on Postural Changes in Pulmonary Function in Obese Subjects: A Longitudinal Study
}

\author{
Mustapha Sebbane MD PhD, Moez El Kamel MD, Alice Millot MD, Boris Jung MD PhD, \\ Sophie Lefebvre PhD, Josh Rubenovitch MD, Grégoire Mercier MD PhD, \\ Jean-Jacques Eledjam MD PhD, Samir Jaber MD PhD, and Maurice Hayot MD PhD
}

\begin{abstract}
BACKGROUND: Postural changes are known to affect normal lung volumes. A reduction in sitting to supine functional residual capacity (FRC) is well-described in non-obese subjects adopting a supine position. However, postural changes in lung volumes in the obese require further exploration. We aimed to longitudinally address the effects of weight loss on postural changes in lung volumes and pulmonary function in obese subjects. We tested the hypothesis that supine reduction in FRC would be absent in morbid obesity and recovered upon weight loss. METHODS: This was a prospective, observational, longitudinal study. Consecutive morbidly obese adults $(N=12$, age: $44 \pm 14 \mathrm{y}$, body mass index: $45 \pm 5 \mathrm{~kg} / \mathrm{m}^{2}$ ) enrolled in a bariatric surgery program were included. Standard pulmonary function tests and blood gas analysis were performed both before and $1 \mathrm{y}$ after surgery. Pulmonary function was assessed in both the sitting and supine position using spirometry and multi-breath helium dilution. Parameters recorded before and after weight loss were compared. The main outcome measure was FRC. RESULTS: Ten subjects were retested 1 y after surgery (body mass index: $31 \pm 5 \mathrm{~kg} / \mathrm{m}^{2}$ ). FRC was not affected by change in posture before surgery. Supine reduction in FRC was observed after weight loss $(\triangle F R C:-0.6 \pm 0.4 \mathrm{~L}$, sitting vs supine, $P=.002$ ). Pulmonary gas exchange improved (alveolar-to-arterial oxygen partial pressure difference: $-8 \pm 11 \mathrm{~mm} \mathrm{Hg}, P=.035)$. CONCLUSIONS: Although postural change in FRC is absent when the morbidly obese adopt a supine position, supine reduction in FRC can be recovered following gastroplasty-induced weight loss, despite residual mild to moderate obesity. This also shows that mild to moderate obesity may affect supine FRC more than morbid obesity. (ClinicalTrials.gov registration NCT02207192.) Key words: lung function; obesity; weight loss; postural change; pulmonary function test; functional residual capacity; bariatric surgery. [Respir Care 2015;60(7):992-999. (C) 2015 Daedalus Enterprises]
\end{abstract}

\section{Introduction}

Obesity has become a worldwide health concern. ${ }^{1}$ The prevalence of obese adults in the United States has risen

\footnotetext{
Drs Sebbane, Lefebvre, Rubenovitch, and Eledjam are affiliated with the Département des Urgences, Hôpital Lapeyronie; Dr Mercier is affiliated with the Département d'Information Médicale, Hôpital Lapeyronie; Drs El Kamel, Millot, Jung, and Jaber are affiliated with the Département d'Anesthésie-Réanimation B, Hôpital St Eloi; and Drs Jung, Jaber, and Hayot are affiliated with PhyMedExp, University of Montpellier, INSERM U1046, CNRS UMR 9214, CHRU de Montpellier, Montpellier, France.
}

This study was supported by the Centre Hospitalier Régional Universitaire Montpellier. The authors have disclosed no conflicts of interest. significantly over the last decade to $32.2 \%$, with morbid obesity increasing at even faster rates. ${ }^{2}$ In Europe, while half of all adults are overweight, $10-20 \%$ of men and $15-25 \%$ of women are obese. In France, the prevalence of adult obesity has increased progressively in both men and women, from $8.6 \%$ in 1997 to $14.5 \%$ in $2009 .^{3}$

\footnotetext{
Correspondence: Mustapha Sebbane MD PhD, Département des Urgences, Centre Hospitalier Régional Universitaire Lapeyronie, 371, avenue du doyen Gaston Giraud, 34295 Montpellier Cedex 5, France. E-mail: m-sebbane@chu-montpellier.fr.
}

DOI: $10.4187 /$ respcare. 03668 
The accumulation of excess body fat is the most common metabolic disorder in humans. It is a major cause of cardiac and metabolic related morbidity and mortality. Many studies have demonstrated an association between excess weight or weight gain and pulmonary dysfunction, ${ }^{4}$ including a reduction in lung volumes. ${ }^{5}$ More specifically, functional residual capacity (FRC) and expiratory reserve volume as well as, to some extent, total lung capacity (TLC) and residual volume (RV) are decreased in obesity. Both FRC and expiratory reserve volume are the most consistently reported findings, with an exponential relationship between body mass index (BMI) and either FRC or expiratory reserve volume. ${ }^{5}$ Weight gain also tends to be accompanied by a decrease in vital capacity (VC) and $\mathrm{FEV}_{1}$, probably attributable to the effect of excess fat mass on chest-wall and lung compliance. Inversely, weight loss has been found to be associated with improved respiratory function. ${ }^{6-11}$

Postural changes are known to affect normal lung volumes due to the gravitational effects of the abdominal contents on the diaphragm's position. More specifically, a reduction in sitting to supine FRC is well-described in non-obese subjects adopting a supine position. Postural changes in lung volumes have also been studied in obesity. ${ }^{12-14}$ Although a significant supine reduction in FRC has also been reported in mild to moderate obesity, its absence has been shown in morbid obesity. ${ }^{15,16}$ However, most studies have compared obese subjects to normal weight controls. Data from longitudinal evaluation of postural changes in lung volumes in morbidly obese individuals following weight loss is scarce.

In the present study, we longitudinally assessed the relationship between weight loss and postural changes in lung volumes. We tested the hypothesis that lack of postural change in FRC would be observed in morbid obesity, whereas supine reduction in FRC would be recovered upon weight loss. We followed morbidly obese subjects over 1 y following bariatric surgery. Changes in lung volumes and air flows were examined in both sitting and supine positions, before and after weight loss. Arterial blood gases were assessed in the sitting position to evaluate the effect of weight loss on pulmonary gas exchange.

\section{Methods}

The study was conducted from August 2005 to May 2007 in the Department of Clinical Physiology of an urban-based university hospital in Montpellier, France. The study was approved by the local ethics committee (Ethical Committee 040506, CPP Sud-Méditterranée IV, Montpellier, France) on October 26th, 2004, and subjects' written informed consent was obtained.

\section{QUICK LOOK}

\section{Current knowledge}

Postural changes are known to affect normal lung volumes due to the gravitational effects of the abdominal contents on the position of the diaphragm. A reduction in functional residual capacity (FRC) from sitting to supine is well described in non-obese subjects. A significant supine reduction in FRC was also reported in mild to moderate obesity, but its absence was shown in morbid obesity.

\section{What this paper contributes to our knowledge}

This longitudinal study demonstrated a lack of FRC reduction when morbidly obese subjects adopted a supine position. Following gastroplasty-induced weight loss, subjects demonstrated a reduction in FRC when adopting the supine position in spite of mild to moderate obesity. The study also demonstrated that mild to moderate obesity affects supine FRC more than morbid obesity.

\section{Population}

Sample size was based on data from a study by Benedik et al, ${ }^{14}$ which includes the largest series of overweight, mildly obese, and moderately obese subjects in the literature $(N=32)$. Sample size calculation for paired difference between supine and seated FRC indicated that 10 subjects would be required to show a mean paired difference in FRC sitting versus supine $=0.5 \mathrm{~L}$, with standard deviation $=0.5, \alpha=0.05$, and power $(1-\beta)=0.8$.

Twelve consecutive subjects scheduled for bariatric surgery were prospectively recruited. Subjects with respiratory and cardiac history (asthma, COPD, heart failure) were excluded. Obstructive sleep apnea was defined as an apnea-hypopnea index greater than 10 , using overnight polysomnography. Subjects were 3 men and 9 women (age: $44 \pm 14$ y [18-61], BMI: $45 \pm 5 \mathrm{~kg} / \mathrm{m}^{2}$ [40-55]). Six subjects had smoking histories (mean pack-years: 21 [8-30]), and 6 were diagnosed with obstructive sleep apnea (mean apnea-hypopnea index: 36 [30-76]).

Bariatric surgery was performed by laparoscopy under general anesthesia. Following surgery, all subjects were put on a specific weight-loss program. Pulmonary function and arterial blood gases were assessed both before and after weight loss as part of preoperative and 12-month follow-up evaluations.

\section{Height, Body Weight, and BMI Measurements}

Height $(\mathrm{m})$ and body weight $(\mathrm{kg})$ were routinely measured as part of preoperative and 12-month follow-up eval- 
uations. BMI was calculated as weight $/ \mathrm{height}^{2}\left(\mathrm{~kg} / \mathrm{m}^{2}\right)$. Weight loss was calculated as values at baseline minus values at $1 \mathrm{y}$.

\section{Pulmonary Function Measurements}

Pulmonary function tests were performed in the sitting and then in the supine position, in accordance with the 2005 American Thoracic Society/European Respiratory Society recommendations. ${ }^{17,18}$ Dynamic and static lung volumes including TLC, FVC, FRC, RV, and expiratory reserve volume subdivisions, as well as $\mathrm{FEV}_{1}$ were measured using spirometry and the multi-breath helium dilution method. Spirometry tests were performed using automated equipment (Hyp Air compact+, Medisoft, Sorinnes, Belgium). The best value obtained from the maximum expiratory flow-volume curves was retained for $\mathrm{FEF}_{75 \%}$, $\mathrm{FEF}_{50 \%}$, and $\mathrm{FEF}_{25 \%}$. Results were reported as absolute and percentage of predicted values.

\section{Arterial Blood Gas Measurements}

Blood samples were withdrawn from the radial artery, with the subject at rest, sitting and breathing room air. Arterial blood gas values, including $\mathrm{P}_{\mathrm{aO}_{2}}$ and $\mathrm{P}_{\mathrm{aCO}_{2}}$, oxygen saturation $\left(\mathrm{S}_{\mathrm{aO}_{2}}\right)$, and $\mathrm{pH}$ concentration were measured at the pulmonary function testing laboratory using a blood gas analyzer (Cobas B221 system, Roche Omnis, Meylan, France). Alveolar-to-arterial oxygen partial pressure difference $\left(\mathrm{P}_{(\mathrm{A}-\mathrm{a}) \mathrm{O}_{2}}\right)$ was calculated as the difference between $\mathrm{P}_{\mathrm{AO}_{2}}$ and $\mathrm{P}_{\mathrm{aO}}$, with the alveolar partial pressure in oxygen $\left(\mathrm{P}_{\mathrm{AO}_{2}}\right)$ obtained from the ideal alveolar gas equation. ${ }^{19}$

\section{Statistical Analysis}

The Kolmogorov-Smirnov test was performed to test normal distribution. When data were normally distributed, description of quantitative variables was presented as means and standard deviations or percentage (\%), with the value range. Paired Student $t$ tests of significance were used to compare parameters recorded before and after weight loss. Non-parametric tests were performed in case of non-normal distribution. The non-parametric Spearman correlation coefficient was used to test relationships between supine reduction in FRC and BMI.

Statistical analyses were carried out using a statistical software package (StatView 5.0, SAS Institute, Cary, North Carolina). A $P<.05$ was considered as statistically significant.

\section{Results}

Two subjects were lost to follow-up. Mean baseline parameters of the 10 subjects retested $1 \mathrm{y}$ after bariatric
Table 1. Characteristics of the Study Participants

\begin{tabular}{lc}
\hline \multicolumn{1}{c}{ Parameters } & Values \\
\hline Subjects $(N)$ & 10 \\
Sex ratio $(\mathrm{M} / \mathrm{F})$ & $2 / 8$ \\
Age $(\mathrm{y})$ & $45 \pm 15(18-61)^{*}$ \\
BMI $\left(\mathrm{kg} / \mathrm{m}^{2}\right)$ & $44 \pm 4(40-50)^{*}$ \\
Smoking history $(n)$ & $5 / 10$ \\
Pack-years $(n)$ & $22(8-30) \dagger$ \\
Apnea-hypopnea index $($ events/h) & $35(21-76) \dagger$ \\
Obstructive sleep apnea $(n)$ & $5 / 10$ \\
& \\
\hline $\begin{array}{l}\text { Data show baseline characteristics of the } 10 \text { morbidly obese adults tested before surgery and } \\
\text { at } 1 \text { y follow-up. }\end{array}$ & \\
$*$ Values are means \pm SD, with range in parentheses. & \\
$\dagger$ Malues are means, with range in parentheses. & \\
F $=$ male & \\
BMI = body male & \\
\hline
\end{tabular}

surgery did not differ from those of the 12 subjects originally included (Table 1). At $1 \mathrm{y}$ follow-up, mean BMI was $31 \pm 5(22-37) \mathrm{kg} / \mathrm{m}^{2}$. Mean reduction in BMI was $12.8 \pm 5.7 \mathrm{~kg} / \mathrm{m}^{2}$, range $4.3-23.8, P=.001$; mean reduction in body weight was $34 \pm 16 \mathrm{~kg}(29 \pm 12 \%$ of initial weight), range $13-64, P=.001$.

\section{Changes in Lung Volumes and Flows Before Surgery}

Baseline lung volumes and expiratory flows measured before surgery are shown in Table 2 . In the sitting position, most lung volumes, including VC, TLC, and RV, remained within normal ranges. Baseline FRC and expiratory reserve volume were below predicted values, with FRC and expiratory reserve volume down to $84 \%$ and $73 \%$ of predicted values, respectively.

On adopting the supine position, a significant decrease in expiratory reserve volume was observed. TLC, VC, and $\mathrm{RV}$ were not significantly affected by the change in posture. No significant decrease in FRC was recorded (Fig. 1).

Flows were within the normal range of predicted values. $\mathrm{FEV}_{1}, \mathrm{FEF}_{50 \%}$, and $\mathrm{FEV}_{1} / \mathrm{VC}$ decreased significantly upon adopting the supine position.

\section{Changes in Lung Volumes and Flows After Weight Loss}

At $1 \mathrm{y}$ follow-up, ventilatory parameters measured in the sitting position tended to improve with weight loss (Table 2, Fig. 1). VC and expiratory reserve volume significantly increased, whereas TLC, FRC, and RV were not significantly modified. Pulmonary flows also improved slightly.

On adopting the supine position, FRC and expiratory reserve volume decreased significantly when compared with sitting position values. VC, TLC, and RV decreased slightly, although the differences were not statistically sig- 


\section{Postural Lung Volumes Changes in Obesity}

Table 2. Respiratory Parameters Measured in Both the Sitting and Supine Position, in the 10 Patients Tested Before and After Weight Loss

\begin{tabular}{|c|c|c|c|c|c|}
\hline \multirow{2}{*}{ Variables } & \multicolumn{2}{|c|}{ Before Weight Loss } & \multicolumn{2}{|c|}{ After Weight Loss } & \multirow{2}{*}{$\begin{array}{c}\text { Before vs After Weight } \\
\text { Loss } \\
(P)\end{array}$} \\
\hline & Absolute Value \pm SD & $\%$ Predicted $\pm \mathrm{SD}$ & Absolute Value \pm SD & $\%$ Predicted $\pm \mathrm{SD}$ & \\
\hline \multicolumn{6}{|l|}{ TLC (L) } \\
\hline Sitting & $5.1 \pm 0.6$ & $101 \pm 14$ & $5.1 \pm 0.6$ & $101 \pm 10$ & .54 \\
\hline Supine & $5.2 \pm 0.6$ & $101 \pm 11$ & $5.0 \pm 0.5$ & $99 \pm 10$ & .44 \\
\hline Sitting vs supine $(P)$ & .855 & & .744 & & \\
\hline \multicolumn{6}{|l|}{$\mathrm{VC}(\mathrm{L})$} \\
\hline Sitting & $3.4 \pm 0.7$ & $106 \pm 15$ & $3.7 \pm 0.6$ & $115 \pm 15$ & .008 \\
\hline Supine & $3.3 \pm 0.7$ & $103 \pm 15$ & $3.6 \pm 0.5$ & $113 \pm 15$ & .04 \\
\hline Sitting vs supine $(P)$ & .06 & & .73 & & \\
\hline \multicolumn{6}{|l|}{$\mathrm{RV}(\mathrm{L})$} \\
\hline Sitting & $1.7 \pm 0.6$ & $100 \pm 32$ & $1.5 \pm 0.4$ & $88 \pm 30$ & .13 \\
\hline Supine & $1.8 \pm 0.4$ & $107 \pm 21$ & $1.5 \pm 0.3$ & $85 \pm 19$ & .001 \\
\hline Sitting vs supine $(P)$ & .21 & & .29 & & \\
\hline \multicolumn{6}{|c|}{ Expiratory reserve volume (L) } \\
\hline Sitting & $0.7 \pm 0.2$ & $73 \pm 20$ & $1.0 \pm 0.3$ & $108 \pm 32$ & .05 \\
\hline Supine & $0.37 \pm 0.1$ & $39 \pm 15$ & $0.4 \pm 0.3$ & $47 \pm 28$ & .39 \\
\hline Sitting vs supine $(P)$ & .001 & & .002 & & \\
\hline \multicolumn{6}{|l|}{ FRC $(\mathrm{L})$} \\
\hline Sitting & $2.3 \pm 0.4$ & $84 \pm 19$ & $2.5 \pm 0.3$ & $89 \pm 14$ & .22 \\
\hline Supine & $2.1 \pm 0.4$ & $77 \pm 15$ & $1.9 \pm 0.3$ & $68 \pm 13$ & .06 \\
\hline Sitting vs supine $(P)$ & .08 & & .002 & & \\
\hline \multicolumn{6}{|l|}{$\mathrm{FEV}_{1}(\mathrm{~L})$} \\
\hline Sitting & $2.69 \pm 0.63$ & $97 \pm 12$ & $2.83 \pm 0.58$ & $105 \pm 14$ & .002 \\
\hline Supine & $2.48 \pm 0.60$ & $90 \pm 14$ & $2.67 \pm 0.54$ & $99 \pm 16$ & .002 \\
\hline Sitting vs supine $(P)$ & .002 & & .044 & & \\
\hline \multicolumn{6}{|l|}{$\mathrm{FEV}_{1} / \mathrm{VC}(\%)$} \\
\hline Sitting & $79 \pm 6$ & $98 \pm 8$ & $77 \pm 6$ & $93 \pm 9)$ & .48 \\
\hline Supine & $75 \pm 8$ & $93 \pm 11$ & $74 \pm 10$ & $96 \pm 8)$ & .38 \\
\hline Sitting vs supine $(P)$ & .023 & & .58 & & \\
\hline \multicolumn{6}{|l|}{$\mathrm{FEF}_{50 \%}(\mathrm{~L} / \mathrm{s})$} \\
\hline Sitting & $3.6 \pm 1.2$ & $88 \pm 27$ & $3.9 \pm 1.2$ & $99 \pm 29)$ & .012 \\
\hline Supine & $3.2 \pm 1.2$ & $78 \pm 27$ & $3.5 \pm 1.4$ & $86 \pm 29)$ & .001 \\
\hline Sitting vs supine $(P)$ & .007 & & .001 & & \\
\hline $\begin{array}{l}\text { Values are expressed as mea } \\
\text { parameters measured before } \\
\text { TLC }=\text { total lung capacity } \\
\text { VC }=\text { vital capacity } \\
\mathrm{RV}=\text { residual volume } \\
\mathrm{FRC}=\text { functional residual ca } \\
\mathrm{FEF}_{50 \%}=\text { forced expiratory }\end{array}$ & $\begin{array}{l}\text { values or percent of predicted } \\
\text { ht loss or in the sitting vs supin }\end{array}$ & $\begin{array}{l}\text { alues of } 10 \text { patients tested } \\
\text { posture. }\end{array}$ & oth before and $1 \mathrm{y}$ after weight 1 & oss. $P<.05$ indicates signi & cant differences between \\
\hline
\end{tabular}

nificant. Postural changes in TLC, FRC, and RV are depicted in Figure 1.

Forced expiratory volumes and flows decreased slightly on adopting the supine position, after weight loss (Table 2).

\section{Postural Changes in FRC When Moving From the Sitting to Supine Position}

Individual sitting to supine changes in FRC recorded in our 12 morbidly obese subjects are displayed in Figure 2. Mean difference in postural change in FRC was $-0.10 \pm 0.28 \mathrm{~L}(P=.098)$ at baseline and reached $-0.6 \pm 0.4 \mathrm{~L}(P=.002)$ at $1 \mathrm{y}$ follow-up. The recovered decrease in FRC was significant $(P=.002$, before vs after weight loss).

No correlation was found between supine reduction in FRC and BMI $(\mathrm{r}=-0.28(P=.43)$ and $\mathrm{r}=0.27(P=.44)$ before and $1 \mathrm{y}$ after surgery, respectively).

\section{Pulmonary Gas Exchange}

Mean $\mathrm{P}_{\mathrm{aCO}}, \mathrm{S}_{\mathrm{aO}}$, and $\mathrm{pH}$ values were within their normal ranges before surgery, and were not modified after 

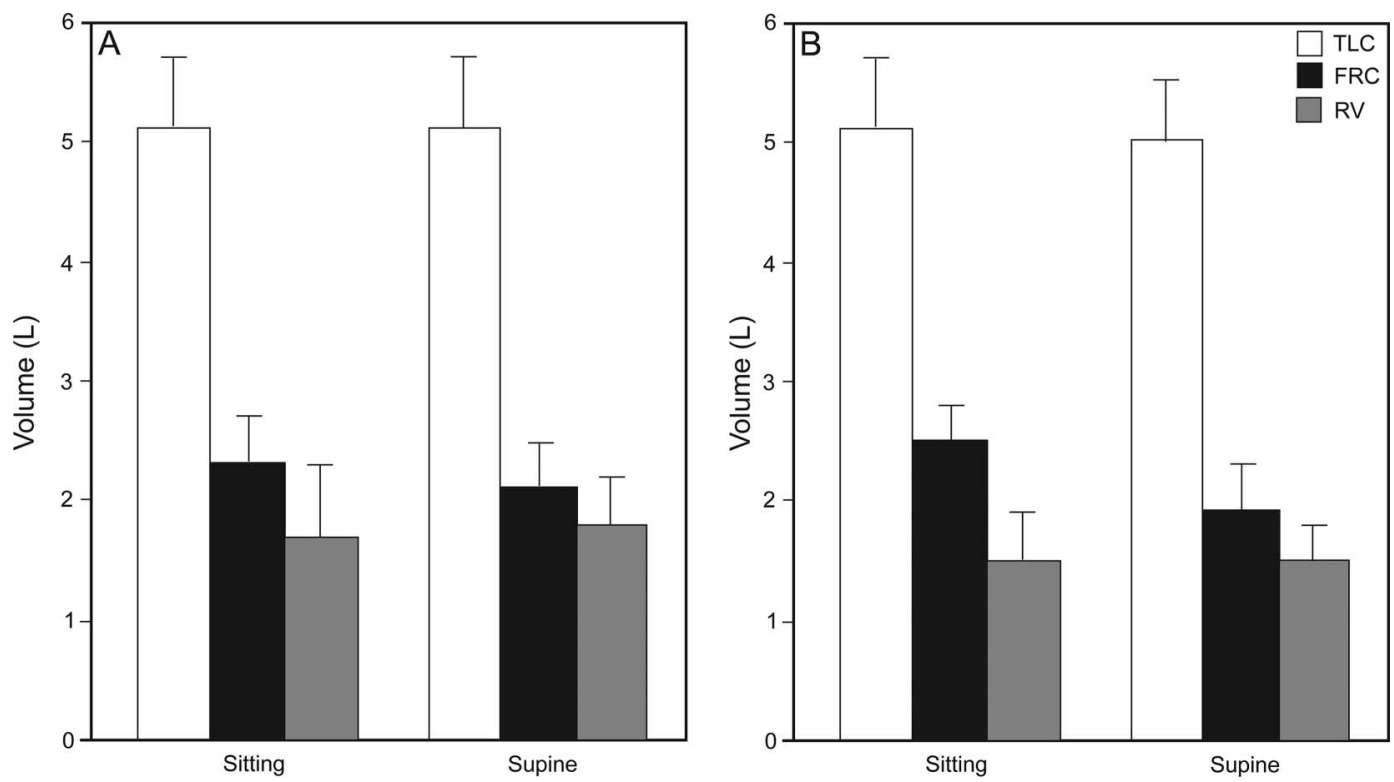

Fig. 1. Total lung capacity (TLC), functional residual capacity (FRC), and residual volume (RV), tested in sitting and supine position, before (A) and 1 y after (B) bariatric surgery and weight loss in 10 subjects. Lung volumes were measured by multi-breath helium dilution. Volumes are shown as means \pm SD.
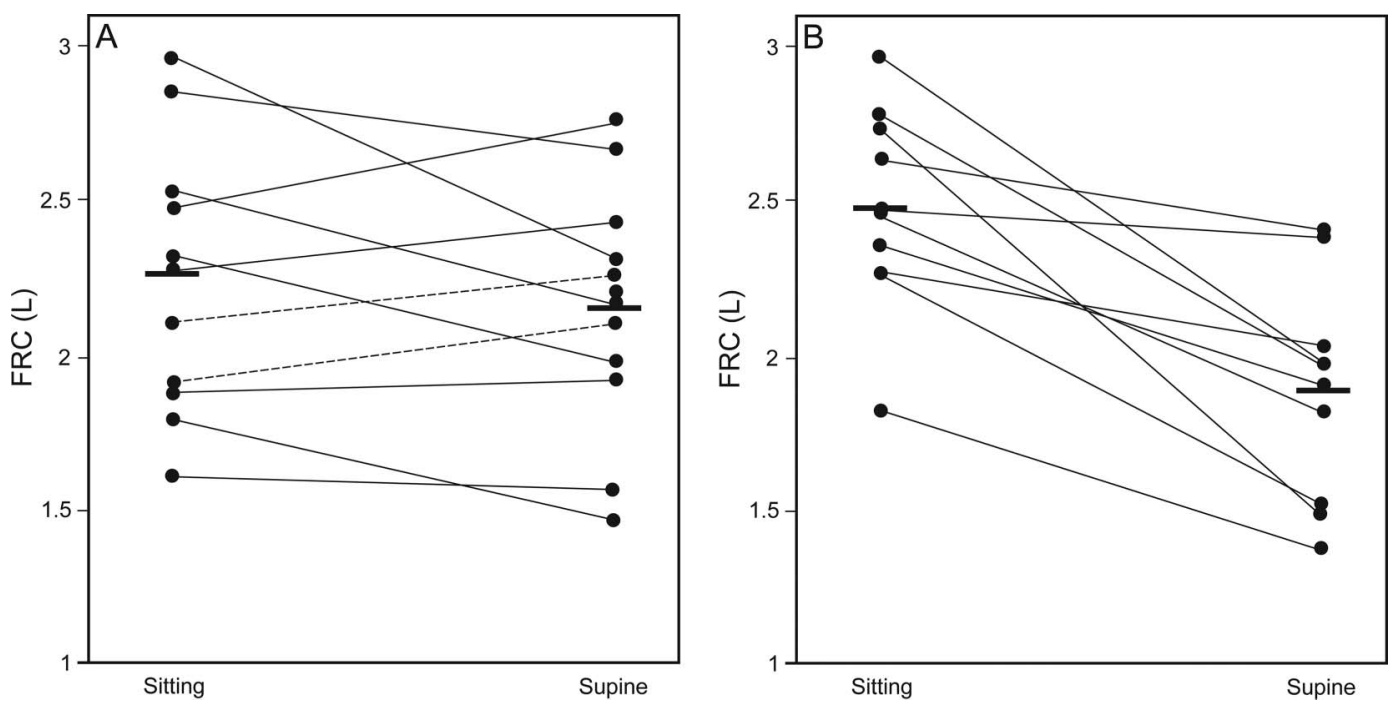

Fig. 2. Individual changes in functional residual capacity (FRC), from the sitting to supine position before and after bariatric surgery and weight loss. Dots show individual FRC values. Horizontal bars represent the mean FRC value. A: Before bariatric surgery $(n=12)$. $P=.098$ for mean FRC values sitting versus supine. Dotted lines show the 2 subjects not retested $1 \mathrm{y}$ after surgery. B: One y after bariatric surgery $(n=10) . P=.01$ for mean $\mathrm{FRC}$ value sitting versus supine.

weight loss (Table 3). Mean $\mathrm{P}_{\mathrm{aO}_{2}}$ values were within the normal range before surgery, although a slight hypoxemia was observed in 5 subjects. A return to the normal range was noted in $3 / 5$ subjects following weight loss (data not shown). The mean $\mathrm{P}_{(\mathrm{A}-\mathrm{a}) \mathrm{O}_{2}}$ was higher in morbidly obese subjects, and returned to the normal range after $1 \mathrm{y}$, with a significant difference before and after weight loss $\left(\Delta \mathrm{P}_{(\mathrm{A}-\mathrm{a}) \mathrm{O}_{2}}=-8.4 \pm 10.7 \mathrm{~mm} \mathrm{Hg}, P=.035\right)$.

\section{Discussion}

Our study is, to our knowledge, the first longitudinal study to examine the effect of weight loss on postural changes in lung volumes, when the morbidly obese become mildly to moderately obese. We specifically demonstrate that supine reduction in FRC can be recovered following gastroplasty-induced weight loss, despite resid- 
Table 3. Pulmonary Gas Exchange Parameters in 10 Obese Adults Measured Prior to Bariatric Surgery and at 1 y Follow-up

\begin{tabular}{lccc}
\hline \hline \multicolumn{1}{c}{ Parameters } & $\begin{array}{c}\text { Before Weight } \\
\text { Loss }\end{array}$ & $\begin{array}{c}\text { After Weight } \\
\text { Loss }\end{array}$ & $P$ \\
\hline $\mathrm{P}_{\mathrm{aO}_{2}}(\mathrm{~mm} \mathrm{Hg})$ & $82 \pm 10$ & $89 \pm 11$ & .11 \\
$\mathrm{P}_{\mathrm{aCO}_{2}}(\mathrm{~mm} \mathrm{Hg})$ & $36 \pm 3$ & $37 \pm 3$ & .47 \\
$\mathrm{pH}$ & $7.41 \pm 0.03$ & $7.41 \pm 0.03$ & .85 \\
$\mathrm{~S}_{\mathrm{aO}_{2}}(\%)$ & $96 \pm 2$ & $97 \pm 1$ & .33 \\
$\mathrm{P}_{(\mathrm{A}-\mathrm{a})}(\mathrm{mm} \mathrm{Hg})$ & $23 \pm 8$ & $14 \pm 7$ & .035
\end{tabular}

Values are mean \pm SD. $P<.05$ indicates statistical significance.

$\mathrm{P}_{\mathrm{aO}_{2}}=$ arterial partial pressure of oxygen

$\mathrm{P}_{\mathrm{aCO}}=$ arterial partial pressure of carbon dioxide

$\mathrm{S}_{\mathrm{aO}_{2}}=$ arterial oxygen saturation

$\mathrm{P}_{(\mathrm{A}-\mathrm{a}) \mathrm{O}_{2}}=$ alveolar-to-arterial oxygen partial pressure difference

ual mild to moderate obesity. We also highlight a greater effect of supine posture on FRC in mild to moderate obesity than in morbid obesity.

The increased seated expiratory reserve volume that we observe upon weight loss confirms consistently reported changes. Expiratory reserve volume is sensitive to body weight modifications, including fat mass reduction. ${ }^{11,20}$ Nonetheless, no significant supine expiratory reserve volume improvement is observed upon weight loss. This may be due to persistent obesity in our subjects.

The slight increase in FRC that we observe upon weight loss is not significant, and varies widely among our subjects.

One year after bariatric surgery, our subjects remain in the mild to moderate obesity range, in which the effect of $\mathrm{BMI}$ on FRC and expiratory reserve volume is pronounced. An exponential relationship between BMI and FRC or expiratory reserve volume has been shown in a large study analyzing pulmonary function test results across BMI ranges. This could contribute to the individual variations recorded among our subjects. ${ }^{5}$

Expiratory reserve volume is the only parameter found to further decrease in our morbidly obese subjects upon adopting the supine position. In contrast, we did not observe any significant postural changes in FRC before surgery.

However, both expiratory reserve volume and FRC are significantly affected by the sitting to supine postural change, following weight loss, 1 y after bariatric surgery, despite residual mild to moderate obesity (mean BMI: $31 \pm 5 \mathrm{~kg} / \mathrm{m}^{2}$ ).

Our results confirm others in showing that TLC and RV are not significantly affected by weight loss or postural changes, ${ }^{15,16,22}$ although modifications in TLC have been reported in some obese subjects. ${ }^{5,23-25}$

Other spirometric variables, such as $\mathrm{VC}$ and $\mathrm{FEV}_{1}$, increased significantly with weight loss induced by gastroplasty.
Unlike $\mathrm{FEV}_{1}$, VC is not affected by body position before surgery. Accordingly, the $\mathrm{FEV}_{1} / \mathrm{VC}$ ratio shows further significant decrease when adopting the supine position. This may suggest an additional effect of the supine position: reducing large airway caliber in the morbidly obese.

In our morbidly obese subjects, expiratory flows were within the normal range, with slight alterations observed in the lower volumes of vital capacity. Before surgery, a significant decline in $\mathrm{FEF}_{50 \%}$ was observed in the supine position. $\mathrm{FEF}_{50 \%}$ values were significantly improved following weight loss both in the sitting and supine positions. However, $\mathrm{FEF}_{50 \%} / \mathrm{VC}$ remained unchanged, and no significant supine reduction was recorded. This may be in favor of an improvement in lung volumes, with decreased airway obstruction after weight loss.

This longitudinal study confirms the sparse evidence in the literature of the different effects of body position on lung volumes depending on BMI range, as shown separately in the morbidly obese ${ }^{15,16}$ and mildly to severely obese groups. ${ }^{13,14,21}$

In non-obese subjects, the decrease in FRC upon adopting the supine position is essentially attributed to the gravitational effects of the abdominal contents. The resulting relaxed diaphragm position displaces the static pressurevolume curve of the chest wall to a smaller volume, increasing the work of breathing. ${ }^{15}$ Modifications of the thoraco-pulmonary compliance, especially that of the chest wall, may also be involved. Increased intrathoracic blood volume could induce a small reduction in TLC and VC, and further contribute to the supine reduction in FRC. ${ }^{26}$

The mechanisms responsible for the lack of supine change in FRC observed in morbidly obese subjects have not yet been clearly established. Static mechanical changes of the lung and chest wall are likely to be involved. Further thoracic compression upon assuming a supine position could be compromised, due to maximal upward displacement of the diaphragm in the upright posture. Additionally, increased chest wall stiffness resulting from fat mass deposits could affect thoracic compliance. Expiratory flow limitation with distal airway closure, causing increased air volume trapping in the distal airspaces, has also been proposed. ${ }^{15,27}$ We did find slightly decreased expiratory flows suggestive of expiratory flow limitation in the distal airways in our morbidly obese subjects adopting a supine position Recently, higher than normal intrathoracic pressure related to increased intra-abdominal pressure has been described in morbidly obese subjects at end-expiration. When changing from the seated to supine position, an increase in intrathoracic pressure combined with a decrease in intra-abdominal pressure was recorded. This resulted in pressure equilibration between the abdominal and thoracic compartment in the morbidly obese in the supine position. ${ }^{28}$ 


\section{Postural Lung Volumes Changes in Obesity}

We hypothesize that reduced chest wall stiffness following loss of chest wall fat as well as the cumulative loss of both chest and abdominal fat may be responsible for reduced intra-abdominal and intrathoracic pressures. The resulting increased transdiaphragmatic pressure and consequent cephalic shift of the diaphragm may explain the recovered decrease in FRC observed in our mild to moderately obese subjects, 1 y after bariatric surgery. Improved expiratory flows following surgically induced weight loss may also have contributed to the recovered supine fall in FRC.

Our results also confirm that improved static lung volumes associated with weight loss further contribute to improved pulmonary gas exchange. ${ }^{11} \mathrm{We}$ observed improved pulmonary gas exchange after weight loss, as reflected by a significant reduction in the mean alveolar-to-arterial oxygen partial pressure difference; this is probably related to a lower ventilation-perfusion mismatch. Although not statistically significant, the combined slight changes in $\mathrm{P}_{\mathrm{aO}_{2}}$ and $\mathrm{P}_{\mathrm{aCO}_{2}}$ values observed after weight loss may have contributed to the reduced $\mathrm{P}_{(\mathrm{A}-\mathrm{a}) \mathrm{O}_{2}}$. Reduced oxygen consumption and $\mathrm{CO}_{2}$ production may also be involved. However, these parameters were not measured.

Our findings corroborate previous data describing improvement in arterial oxygenation with massive weight loss $\left(\Delta \mathrm{BMI}>20 \mathrm{~kg} / \mathrm{m}^{2}\right){ }^{6}$ However, a review of the literature found better $\mathrm{P}_{\mathrm{aO}}$ (by $10 \mathrm{~mm} \mathrm{Hg}$, range $1-23 \mathrm{~mm} \mathrm{Hg}$ ) as well as reduced $\mathrm{P}_{(\mathrm{A}-\mathrm{a}) \mathrm{O}_{2}}$ (by $-8 \mathrm{~mm} \mathrm{Hg}$, range -3 to $-16 \mathrm{~mm} \mathrm{Hg}$ ) and $\mathrm{P}_{\mathrm{aCO}}$ values (by $-3 \mathrm{~mm} \mathrm{Hg}$, range 3 to $-14 \mathrm{~mm} \mathrm{Hg}$ ) for a mean $\Delta \mathrm{BMI}$ of $-13 \mathrm{~kg} / \mathrm{m}^{2} .^{29}$ The better gas exchange at rest described in morbidly obese women compared with men, attributed to lower waist-tohip ratios in women, ${ }^{30}$ may explain the minor difference in $\mathrm{P}_{\mathrm{aO}_{2}}$ and $\mathrm{P}_{\mathrm{aCO}}$ values recorded before and after weight loss in our cohort (sex ratio [M/F]: 2/8). ${ }^{29}$

\section{Limitations}

This study is limited by the small number of subjects, preventing further investigation such as the possible role of gender or adiposity distribution.

Indeed, although the distribution of obesity can play a role in pulmonary function, $23,31,32$ the cumulative effect of overall chest wall size, rather than changes in any specific regional chest wall fat may be involved, as shown in moderately obese men. ${ }^{33}$ Neither the waist-to-hip ratio nor the body fat distribution was measured in our study.

\section{Conclusions}

Our longitudinal study demonstrates a lack of supine reduction in FRC when morbidly obese subjects adopt a supine position. The recovery of supine FRC reduction following gastroplasty-induced weight loss is also demon- strated, despite residual mild to moderate obesity. Furthermore, mild to moderate obesity was shown to affect supine FRC more than morbid obesity.

\section{ACKNOWLEDGMENTS}

We thank the volunteers for their participation in the research study, as well as the laboratory technicians at the pulmonary function test laboratory for their kind help and support. We are grateful to Drs Jonathan R Clarke and Julie Carr for English revisions.

\section{REFERENCES}

1. Calle EE, Thun MJ, Petrelli JM, Rodriguez C, Heath CW Jr. Bodymass index and mortality in a prospective cohort of US adults. N Engl J Med 1999;341(15):1097-1105.

2. Ogden CL, Yanovski SZ, Carroll MD, Flegal KM. The epidemiology of obesity. Gastroenterology 2007;132(6):2087-2102.

3. Charles MA, Eschwege E, Basdevant A. Monitoring the obesity epidemic in France: the Obepi surveys 1997-2006. Obesity (Silver Spring) 2008;16(9):2182-2186.

4. Chen Y, Horne SL, Dosman JA. Body weight and weight gain related to pulmonary function decline in adults: a six year follow up study. Thorax 1993;48(4):375-380.

5. Jones RL, Nzekwu MM. The effects of body mass index on lung volumes. Chest 2006;130(3):827-833.

6. Vaughan RW, Cork RC, Hollander D. The effect of massive weight loss on arterial oxygenation and pulmonary function tests. Anesthesiology 1981;54(4):325-328.

7. Thomas PS, Cowen ER, Hulands G, Milledge JS. Respiratory function in the morbidly obese before and after weight loss. Thorax 1989;44(5):382-386.

8. Hakala K, Mustajoki P, Aittomäki J, Sovijärvi AR. Effect of weight loss and body position on pulmonary function and gas exchange abnormalities in morbid obesity. Int $\mathrm{J}$ Obes Relat Metab Disord $1995 ; 19(5): 343-346$

9. El-Gamal H, Khayat A, Shikora S, Unterborn JN. Relationship of dyspnea to respiratory drive and pulmonary function tests in obese patients before and after weight loss. Chest 2005;128(6):3870-3874.

10. Weiner P, Waizman J, Weiner M, Rabner M, Magadle R, Zamir D. Influence of excessive weight loss after gastroplasty for morbid obesity on respiratory muscle performance. Thorax 1998;53(1):39-42.

11. Wei YF, Wu HD. Candidates for bariatric surgery: morbidly obese patients with pulmonary dysfunction. J Obes 2012;2012:878371; doi: 10.1155/2012/878371.

12. Bae J, Ting EY, Giuffrida JG. The effect of changes in the body position obsese patients on pulmonary volume and ventilatory function. Bull NY Acad Med 1976;52(7):830-837.

13. Hakala K, Maasilta $P$, Sovijärvi AR. Upright body position and weight loss improve respiratory mechanics and daytime oxygenation in obese patients with obstructive sleep apnoea. Clin Physiol 2000; 20(1):50-55.

14. Benedik PS, Baun MM, Keus L, Jimenez C, Morice R, Bidani A, Meininger JC. Effects of body position on resting lung volume in overweight and mildly to moderately obese subjects. Respir Care 2009;54(3):334-339.

15. Yap JC, Watson RA, Gilbey S, Pride NB. Effects of posture on respiratory mechanics in obesity. J Appl Physiol 1995;79(4):11991205.

16. Watson RA, Pride NB. Postural changes in lung volumes and respiratory resistance in subjects with obesity. J Appl Physiol 2005;98(2): 512-517. 


\section{Postural Lung Volumes Changes in Obesity}

17. Wanger J, Clausen JL, Coates A, Pedersen OF, Brusasco V, Burgos $\mathrm{F}$ et al. Standardisation of the measurement of lung volumes. Eur Respir J 2005;26(3):511-522.

18. Miller MR, Hankinson J, Brusasco V, Burgos F, Casaburi R, Coates A, et al. Standardisation of spirometry. Eur Respir J 2005;26(2):319338.

19. Nunn JF. Applied respiratory physiology, 4th edition. Oxford: Butterworth-Heinemann; 1993, 28.

20. Salome CM, King GG, Berend N. Physiology of obesity and effects on lung function. J Appl Physiol 2010;108(1):206-211.

21. DeLorey DS, Wyrick BL, Babb TG. Mild-to-moderate obesity: implications for respiratory mechanics at rest and during exercise in young men. Int J Obes 2005;29(9):1039-1047.

22. Zerah F, Harf A, Perlemuter L, Lorino H, Lorino AM, Atlan G. Effects of obesity on respiratory resistance. Chest 1993;103(5):14701476.

23. Collins LC, Hoberty PD, Walker JF, Fletcher EC, Peiris AN. The effect of body fat distribution on pulmonary function tests. Chest 1995;107(5):1298-1302.

24. Rubinstein I, Zamel N, DuBarry L, Hoffstein V. Airflow limitation in morbidly obese, nonsmoking men. Ann Intern Med 1990;112(11): 828-832.

25. Watson RA, Pride NB, Thomas EL, Fitzpatrick J, Durighel G, McCarthy J, et al. Reduction of total lung capacity in obese men: com- parison of total intrathoracic and gas volumes. J Appl Physiol 2010; 108(6): 1605-1612.

26. Tenney SM. Fluid volume redistribution and thoracic volume changes during recumbency. J Appl Physiol 1959;14(1):129-132.

27. Pankow W, Podszus T, Gutheil T, Penzel T, Peter J, Von Wichert P. Expiratory flow limitation and intrinsic positive end-expiratory pressure in obesity. J Appl Physiol 1998;85(4):1236-1243.

28. Steier J, Lunt A, Hart N, Polkey MI, Moxham J. Observational study of the effect of obesity on lung volumes. Thorax 2014;69(8):752759 .

29. Zavorsky GS, Hoffman SL. Pulmonary gas exchange in the morbidly obese. Obes Rev 2008;9(4):326-339.

30. Zavorsky GS, Murias JM, Kim do J, Gow J, Sylvestre JL, Christou NV. Waist-to-hip ratio is associated with pulmonary gas exchange in the morbidly obese. Chest 2007;131(2):362-367.

31. Lazarus R, Gore CJ, Booth M, Owen N. Effects of body composition and fat distribution on ventilatory function in adults. Am J Clin Nutr 1998;68(1):35-41.

32. De Lorenzo A, Maiolo C, Mohamed EI, Andreoli A, Petrone-De Luca P, Rossi P. Body composition analysis and changes in airways function in obese adults after hypocaloric diet. Chest 2001;119(5): 1409-1415.

33. Babb TG, Wyrick BL, DeLorey DS, Chase PJ, Feng MY. Fat distribution and end-expiratory lung volume in lean and obese men and women. Chest 2008;134(4):704-711.

This article is approved for Continuing Respiratory Care Education credit. For information and to obtain your CRCE

(free to AARC members) visit 